ERRATA

\title{
Erratum to: Application of Risk-Based Maintenance Using Analytic Hierarchy Process for Selection of Maintenance Policy of Dragline
}

\author{
B. R. Sahoo ${ }^{a}$ and S. K. Palei ${ }^{a *}$ \\ ${ }^{a}$ Department of Mining Engineering, Indian Institute of Technology (B.H.U), \\ Varanasi, 221005 India \\ *e-mail:skpalei.min@iitbhu.ac.in \\ Received November 24, 2018 \\ Revised December 12, 2019 \\ Accepted July 9, 2020
}

DOI: $10.1134 / \mathrm{S} 1062739120057239$

The original online version of this article was revised. In the published version there is an error in the spelling of the article title. The present form in this erratum is the correct: Application of Risk-Based Maintenance Using Analytic Hierarchy Process for Selection of Maintenance Policy of Dragline.

The original article can be found online at https: //doi.org/10.1134/S1062739120046909.

The original article has been corrected. 